\title{
Síndrome de Ehlers-Danlos: Suspeitar e Despistar
}

\section{Ehlers-Danlos Syndrome: Suspect and Exclude}

Ângela Fernandes ${ }^{1}$, Ana Gomes²

PALAVRAS-CHAVE: Anamnese; Instabilidade Articular, Síndrome de Ehlers-Danlos

KEYWORDS: Ehlers-Danlos Syndrome/diagnosis; Joint Instability; Medical History Taking

\section{DESCRIÇÃO DO CASO}

Uma jovem de 22 anos recorreu a consulta com o Médico de Família por queixas de deslocação frequente da articulação esternoclavicular esquerda quando levantava pesos no ginásio, com 1 ano de evolução. Negava traumatismos prévios.

Não possuía antecedentes pessoais de relevo. Como medicação habitual fazia apenas um contracetivo oral combinado. Apresentava antecedentes familiares de hemocromatose (pai e irmão), sem outros antecedentes familiares relevantes conhecidos.

O exame físico revelou luxação não dolorosa da articulação esternoclavicular esquerda com a flexão do ombro. Adicionalmente, foram notados sinais de doença do te- cido conjuntivo: aracnodactilia (Fig. 1), sinal de Walker (Fig. 2), joelho recurvatum, hipermobilidade de múltiplas articulações e hiperextensibilidade cutânea.

Após exame físico completo, procedeu-se à aplicação dos critérios de diagnóstico de síndromes de Ehlers-Danlos, revistos em 2017. ${ }^{1}$ Neste caso, a clínica da doente enquadrava-se no diagnóstico de síndrome de Ehlers-Danlos tipo hipermobilidade. Este diagnóstico é feito quando são cumpridos 3 tipos de critérios:

, Critérios tipo 1: hipermobilidade articular generalizada, avaliada através da escala de hipermobilidade de Beighton;

Critérios tipo 2: presença de outros sinais sistémicos de doença do tecido conjuntivo (hiperextensibilidade

1. Interna de Formação Específica de Medicina Geral e Familiar, USF + Carandá, ACeS Cávado I - Braga, Portugal. 2. Médica Assistente de Medicina Geral e Familiar, USF + Carandá, ACeS Cávado I - Braga, Portugal.

Recebido/Received: 27/08/2019 - Aceite/Accepted: 15/12/2019 - Publicado/Published: 31/12/2019

•Autor (es) (ou seu (s) empregador (es)) 2019. Reutilização permitida de acordo com CC BY-NC. Nenhuma reutilização comercial. ${ }^{\bullet}$ Author(s) (or their employer(s)) 2019. Re-use permitted under CC BY-NC. No commercial re-use. 


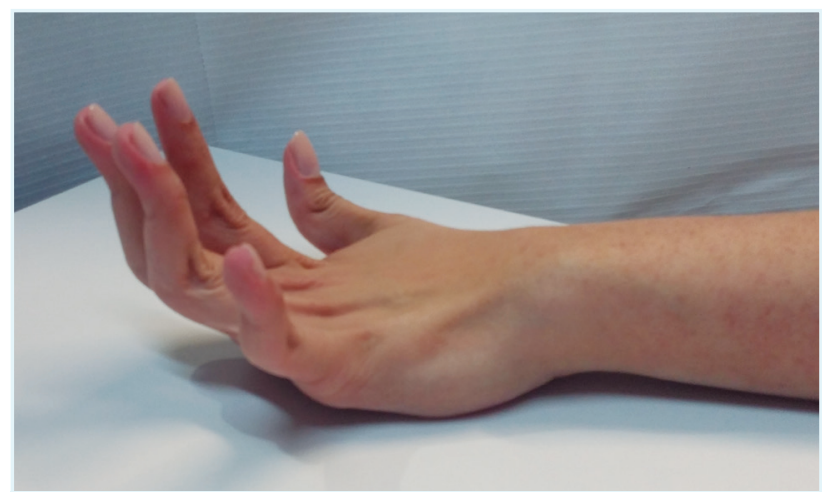

FIGURA 1. Aracnodactilia: dedos longos, finos e com hipermobilidade das articulações metacarpo-falângicas e inter-falângicas.

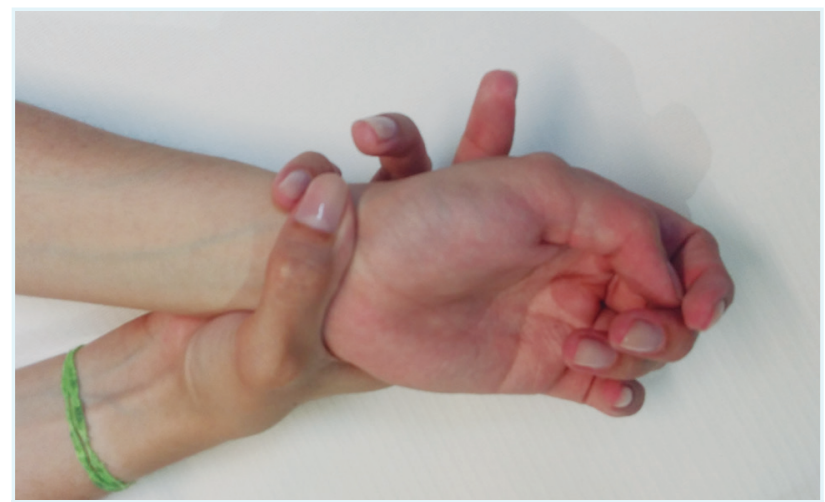

FIGURA 2. Sinal de Walker. Sobreposição das falanges distais do polegar e $5^{\circ}$ dedo quando a mão rodeia o punho oposto.

cutânea, pele suave, estrias, pápulas piezogénicas) e/ou história familiar positiva e/ou complicações musculoesqueléticas (pelo menos 2);

Critérios tipo 3: ausência de fragilidade cutânea significativa que leve à suspeita de outras síndromes de Ehlers-Danlos e exclusão de outras doenças do tecido conjuntivo e exclusão de outros diagnósticos que cursam com hipermobilidade articular.

Foram realizados certos meios complementares de diagnóstico para a exclusão de outras síndromes: velocidade de sedimentação, fator reumatoide, anticorpos antinucleares e anticorpos anti ds-DNA (exclusão de doenças autoimunes como artrite reumatoide e lúpus eritematoso sistémico), ecocardiograma (exclusão de síndrome de Marfan) e radiografia da anca bilateral (exclusão de síndrome de Löeys-Dietz). Todos se revelaram normais.

Assim, foi feito o diagnóstico de síndrome de Ehlers-Danlos tipo hipermobilidade.

As síndromes de Ehler-Danlos são um grupo heterogéneo de doenças do tecido conjuntivo. Caracterizam-se por hipermobilidade articular, hiperextensibilidade cutânea e fragilidade dos tecidos, sendo o subtipo de hipermobilidade o mais frequente, com uma prevalência de 1/5000-20 000 pessoas. ${ }^{2}$ O diagnóstico baseia-se na clínica, e estima-se que esteja largamente subdiagnosticada, uma vez que a principal característica clínica é a hipermobilidade articular, muitas vezes desvalorizada como uma variante do normal sem investigação adicional. ${ }^{1} \mathrm{O}$ subtipo hipermobilidade é considerado o menos severo de todo o espectro. ${ }^{1-2}$

Não há tratamento específico. O objetivo é prevenir e tratar possíveis complicações, que derivam da instabilidade articular e laxidez dos tecidos, como osteoartroses precoces e síndromes de dor crónica. ${ }^{3,4}$ Outras complicações são a patologia disautonómica e obstétrica. ${ }^{5,6}$

Neste caso, foi aconselhado tratamento fisiátrico para fortalecimento muscular e ligamentar. Foi feito um aconselhamento pré-conceção, pois quando engravidar, deverá ser encaminhada para consulta de Obstetrícia pelo risco de abortamento por incompetência do canal cervical. ${ }^{6}$

Na presença de hiperlaxidez e hipermobilidade articular, apesar de serem habitualmente variações da normalidade, deve haver a suspeita de doença do tecido conjuntivo. Deve ser feita uma anamnese e exame físico extensos que permitam diferenciar síndromes clinicamente significativas de variações da normalidade, com vista ao tratamento e prevenção eficazes.

CONFLITOS DE INTERESSE: OS autores declaram não ter qualquer conflito de interesse na realização do presente trabalho.

FONTES DE FINANCIAMENTO: Não houve qualquer fonte de financiamento na realização do presente trabalho.

CONFIDENCIALIDADE DOS DADOS: Os autores declaram ter seguido os protocolos da sua instituição acerca da publicação dos dados de doentes.

CONSENTIMENTO: Consentimento do doente para publicação obtido.

PROTEÇÃO DE PESSOAS E ANIMAIS: Os autores declaram que os procedimentos seguidos na elaboração do presente trabalho estão em conformidade com as normas das comissões de investigação clínica e de ética, bem como da declaração de Helsínquia e da Associação Médica Mundial.

PROVENIÊNCIA E REVISÃO POR PARES: Não comissionado; revisão externa por pares.

CONFLICTS OF INTEREST: The authors declare that they have no conflicts of interest.

FINANCIAL SUPPORT: This work has not received any contribution, grant or scholarship. 
CONFIDENTIALITY OF DATA: The authors declare that they have followed the protocols of their work center on the publication of data from patients.

PATIENT CONSENT: Consent for publication was obtained.

PROTECTION OF HUMAN AND ANIMAL SUBJECTS: The authors declare that the procedures followed were in accordance with the regulations of the relevant clinical research ethics committee and with those of the Code of Ethics of the World Medical Association (Declaration of Helsinki).

PROVENANCE AND PEER REVIEW: Not commissioned; externally peer reviewed.

\section{REFERÊNCIAS}

1. Malfait F, Francomano C, Byers P, Belmont J, Berglund B, Black $J$, et al. The 2017 International Classification of the Ehlers-Danlos Syndromes. Am J Med Genet C Semin Med Genet. 2017: 175:8-26.

2. Genetics Home Reference. Ehler-Danlos Syndrome. U.S. National Library of Medicine. [consultado Dez 2019]. Disponível em: https://ghr.nlm.nih.gov/condition/ehlers-danlos-syndrome\#.

3. Rombaut L, Malfait F, Cools A, De Paepe A, Calders P. Musculoskeletal complaints, physical activity and health-related quality of life among patients with the Ehlers-Danlos syndrome hypermobility type. Disabil Rehabil. 2010; 32:1339-45. doi: 10.3109/09638280903514739.

4. Rombaut L, Malfait F, De Wandele I, Cools A, Thijs Y, De Paepe A et al. Medication, surgery, and physiotherapy among patients with the hypermobility type of Ehlers-Danlos syndrome. Arch Phys Med Rehabil. 2010, 92:1106-12. doi: 10.1016/j. apmr.2011.01.016.

5. Gazit Y, Nahir AM, Grahame R, Jacob G. Dysautonomia in the joint hypermobility syndrome. Am J Med. 2003;115:33-40.

6. Hurst B, Lange S, Kullstam S, Usadi R, Matthews M, Marshburn P. Obstetric and gynecologic challenges in women with Ehlers-Danlos syndrome. Obstet Gynecol. 2014:123:506-13. doi: 10.1097/AOG.0000000000000123. 